\title{
ALCOHOL AS AN ETIOLOGICAL FACTOR IN MENTAL DISEASE.
}

By HENRY A. COTTON, M. D.,

Danvers Iusane Hospital, Hathorne, Mass.

There is hardly any question to-day of such importance and interest to us as physicians caring for the insane, as that chosen for this discussion, and although this may be considered a sociological question, still our responsibility for its final solution can not be underestimated.

The progress in general medicine has been largely marked by discoveries of preventive measures and by their practical application, a notable decrease in certain diseases has been effected. So in our province the question of prophylaxis is of even greater importance than in general medicine and we must hope at present for more from this source than from curative measures. We will attempt to show that alcoholic excesses, and even moderate indulgences, are a large factor in producing the increasing ratio of insanity to-day. If we could make the public at large recognize this fact, much would be accomplished toward a solution of this problem. That this question, apart from its religious and moral aspect, has a direct bearing upon race hygiene can not be doubted; but that our counsels and warnings in this direction will be heeded is quite another question.

When it was proved that malaria and yellow fever were directly due to the bite of certain species of mosquito, how quick the public were to see their danger and follow the directions that would rid them of these diseases. The same can be said of smallpox and other diseases. But with the use and abuse of alcohol as in the case in veritreal diseases the public as a whole pays little attention to the counsels of the medical profession and as a result we find a steady increase in the diseases the result of these vices.

White ${ }^{1}$ who is always quoted in regard to this question says

${ }^{1}$ White: Alcohol and drug intoxication. Reference hand-book of the Medical Sciences, Vol. 5, p. 3I. 
"The causes of drinking are intimately varied and infinitely bound up in the heart of man-at once the expression of his strength and his weakness, his success and failures." And in view of this condition we see why it is that our counsels are not followed. Paton ${ }^{3}$ remarks that there is no question to-day that is in greater need of being studied by sober minded individuals. Also that the public instruction has usually been based upon imperfect observation and that the facts are so distorted by fanatical enthusiasm that to say the least, little good thus far has been done.

However, one needs but to review the literature on the subject of alcoholism to see that a great deal of scientific work has been done both in this country and abroad, especially the latter. The opinions expressed are unanimous in regard to the harmful effects of alcohol on the body as well as the mind. In order to obtain some idea of the relation of alcohol to insanity, we must necessarily turn to statistics, which although questionable at times, are the only means we have of forming any opinion of this relation.

For convenience in considering this question, we can divide the etiological effects of alcohol into direct, indirect or accessory, and inherited effects. Under the head of direct, we will consider only the rôle of alcohol in causing distinctive psychoses, attributable to the abuse of this agent alone.

Under the indirect effects we will consider the influence of alcohol as an accessory cause in the production and modification of other psychoses. And under the inherited effects we will consider the effects of parental alcoholism on the offspring.

\section{Alcohol as a Direct Cause.}

That alcohol is directly responsible for certain psychoses that go to make up a relatively large percentage of the admissions to insane hospitals at the present time, cannot be questioned. If one consults the statistics compiled in modern hospitals one is easily convinced that the above is true. That these statistics do not include all the alcoholics is plain, for a great many habitual drinkers, while not legally insane are as much a menace to public safety as those adjudged insane, yet they may never be committed.

2 Paton: Psychiatry, p. 3 ro. 
Also many cases of delirium tremens are treated outside of these hospitals and do not come into the statistics. Because of the above facts, these statistics would underestimate rather than overestimate the conditions as they exist. The proportion of alcoholic insanity to the total insane is placed by various observers from 13 to 30 per cent, according to the community from which they were taken.

Kraepelin ${ }^{2}$ reviews the statistics of the Psychiatric Clinic at Munich for the year ending 1905. Among I 373 persons admitted, 30 per cent of the male patients were suffering from psychoses due directly to alcohol and 6 per cent of the female cases.

The majority of the alcoholic cases admitted were simple drunkenness, while the next largest group were those classed among the chronic types ( 31.5 per cent), and only to per cent of delirium tremens. This small percentage of cases of delirium tremens is explained by Kraepelin by the fact that many such cases are treated outside the clinic. The remainder, less than 20 per cent, were classified as subacute.

It is interesting to compare statistics from a beer-drinking community like Munich, with communities where the people use largely distilled liquors. Kraepelin found no difference in the psychoses caused by malt liquors and those caused by other forms of alcohol, although a great many of his cases indulged in whiskey as well as beer. Mitchell " gives statistics compiled from the admission to the Danvers Insane Hospital for five years ending with the fall of 1903 . He finds that in 13.1 per cent of the male cases out of a total of II 29 admissions (males) alcohol was the direct factor in causing the psychoses. The dipsomaniacs are excluded from this number, as well as cases where alcohol was an accessory factor in producing other psychoses. The percentage of delirium tremens is nearly three times as large as the percentage of such cases admitted to the Munich clinic. This can be accounted for by the different habits of drinking in the two countries as well as by the fact that whiskey is used more freely here than in Germany.

\footnotetext{
'Der Alcoholismus in München. Münchener Medicinische Wochenschrift, April 17, 1906.

- Types of Alcoholic Insanity. American Journal of Insanity, Vol. LXI, p. 25I, October, 1904.
} 
The small percentage of the alcoholic cases reported by Mitchell, is due to the fact that it is an average for five years. It is also true that our present number of alcoholic admissions come very near to the figures given by Kraepelin. That there is an increase in the cases of alcoholic insanity the following figures taken from the annual reports from 1903 to 1906 (Danvers Insane Hospital) will show :

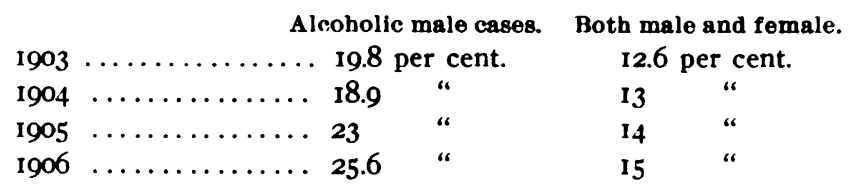

Here we see that the increase in cases for 1906 over 1903 is 6 per cent and over the average for a period of five years before that the increase is 12.6 per cent for the male. These tables are compiled carefully and can be taken as showing fairly accurately the percentage of alcoholic insanity for this period.

\section{Alcohol as an Indirect Cause.}

None the less important is the effect of alcohol as an accessory cause in other psychoses. And here we must again refer to Kraepelin who has compiled so much in the work to which we have referred. He finds that in 44.9 per cent of psychoses not directly due to alcohol this agent was an important factor in producing the mental disturbance. When male cases alone are considered, the percentage reached 6r.8. He further analyzes this percentage in the various psychoses.

Among the epileptics, in 65 per cent of the male cases and 28.5 per cent of the female cases, alcohol could be held responsible for their commitment. It is notably true that in this class of cases alcohol is especially dangerous and directly causes a train of unpleasant symptoms-acts of violence, dreamy states, with tendency to homicide, suicide, and pyromania-besides producing a very unfavorable effect upon the convulsions. Among the psychopathic cases, alcohol played a very important rôle and Kraepelin gives the percentage as 59 in the males and 46.2 in all cases. He considers that alcohol is almost entirely responsible for the mental disturbance in this large number of cases, especially in weakening the already weak and unstable will. In 42.9 per cent of the imbe- 
ciles, alcohol appeared to be responsible for their admission to the clinic. In manic-depressive insanity alcohol was present in 45.5 per cent of the cases but often the abuse of alcohol can be considered as a symptom rather than a cause of this disease, although it modifies to some extent, the nature of the attacks. In traumatic neuroses alcohol also had an unfavorable effect upon the course of the disease, and in arteriosclerosis 64 per cent of the cases are alcoholic. This last refers only to arteriosclerosis as effecting the brain and does not show the percentage of the effects on other parts of the body.

Kraepelin's views on the influence of alcohol in producing general paralysis, while somewhat radical, seems to be based upon sound premises. In this class of cases it was found that in 51.9 per cent of males and in 33.9 per cent of females ( 46.6 per cent in all) alcoholic excesses were present, and he refers especially to early excesses and not the later excesses which may be classed as symptoms of the disease.

This large percentage of cases in which alcohol is present was considered by him as something more than accidental, especially when this is compared with cases of dementia praecox in which disease alcohol has little to do with the causation. In the latter class of cases only 14.4 per cent of the men and 4 per cent of the women were alcoholic. That this discrepancy is more marked in the case of the women, he considers of the utmost importance as showing the harmful effects of alcohol in people previously infected with syphilis. According to him alcohol is responsible for the large ratio of general paralysis in Munich. As a proof of this he cites the relative infrequency of general paralysis in countries where alcohol is but little used. As an example he mentions Java, where only one general paralytic was observed, and Turkey and Arabia, where the disease is almost unknown. The relative infrequency of general paralysis in women as compared to men in other countries, in some instances, only i to 17 , he considers due to the protoction of women from alcoholic abuses. Twenty-five years ago the proportion of female to male cases in Munich was 1 to 5 , but at present it is $I$ to 2 , and he ascribes this increase partially to the use of alcohol. So strongly does Kraepelin feel on this subject that he is convinced that one-third of the cases of general paralysis could be avoided if people with syphilis would 
abstain from alcohol. And when it is taken into account that three-fourths of the infections by syphilis occur when the contracting party is intoxicated, it brings the total of possible prevention by abstinence from alcohol to 80 per cent.

\section{INHERITED EFFECTS OF AlcoHol.}

The hereditary effects of alcohol are better understood when we consider that its harmful effects are transmitted directly to the germ plasm. Inherited alcoholism is believed in by many, meaning in a broad sense a predisposition toward drinking habits and inherited "tastes" for alcohol. If we subscribe to the dictum of biological science to-day, that acquired characters as such are not transmitted, we certainly must ascribe a different rôle of alcohol through heredity. We can more easily harmonize the view that alcoholism in the parents, especially at the time of conception, affects the germ plasm and thus injures it by its toxic effects. This is the conclusion arrived at by modern investigators who have had an opportunity of inquiring more minutely into this subject. Among those who support this view may be mentioned Kraepelin, Forel, and Bevan Lewis. The latter ${ }^{8}$ discusses this subject at length and goes even deeper into the analysis of the effect of parental alcoholism on the germ plasm, and he believes in a separate and distinct effect in paternal and maternal transmission. According to him epilepsy, chorea, hysteria, moral and impulsive types of insanity are the direct results of paternal transmission. In contradistinction to these "explosive" forms the "quiet" forms such as congenital mental weakness, imbecility and idiocy are the results of maternal transmission. This view is upheld by other observers who based their opinions not only on the inherent nature of the male and female elements, but also upon facts gleaned from statistics.

That this matter of the transmission of the toxic effects of alcohol in injuring and interfering with the development of the foetus, is of more than theoretical importance, is easily seen when we consider the practical application of this theory. Forel ${ }^{\circ}$ for ex-

\footnotetext{
- Bevan Lewis. Alcohol, Crime, and Insanity. Journal of Mental Science, April, 1906.

- Forel: Die Alcoholfrage. München, I906.
} 
ample found in some two thousand idiots in Switzerland, that a very large majority had alcoholic parents. He even goes further into his inquiries and finds in a large majority of these cases the date of conception could be definitely placed during carnival and "fest" seasons, at which times, as is well known, the people were accustomed to drink a great deal more than usual and become intoxicated. Many other authors could be cited as upholding this view but I think this is sufficient to arouse interest in this phase of the alcohol question. It is not difficult to believe that the germ plasm is thus affected materially when conception takes place under such unfavorable conditions. This may also explain the accidental occurrence of defective children in families where the other children are normal, and no other causes can be found for these accidents.

If we look at the matter from another point of view, we find that the progeny of habitual drinkers, suffers materially from the effects of alcoholism in the parents. Kraepelin quotes from the investigations of Plaut who observed 29 families in which the father and mother were habitual drinkers. The results found which can partially, at least, be ascribed to alcohol were as follows:

There were 33 miscarriages and 183 living children in these families: 60 or 32.7 per cent died in their first year, and of 98 children personally observed by Plaut, 58 ( 59 per cent) were abnormal ; 35 being nervous and psychopathic, 8 epileptic, 12 imbeciles and 3 idiots. Among the 40 healthy children, 6 were weaklings and retarded in their development, 7 rachitic, 3 scrofulous and I tuberculous; and of the 23 mentally and physically normal, 8 showed distinct stigmata of degeneration. These figures will pretty well coincide with the findings of other investigators and when compared with the children of non-drinkers, the effects of the alcohol are readily seen.

Regarding miscarriages and still-births, it has been shown by various observers that the percentage in alcoholic families is greater than non-alcoholic. In 81 families with alcoholism in the parents, Arrive ${ }^{\gamma}$ found 5.2 per cent of still-births against 2.8 per cent in non-alcoholic families and II.64 per cent of miscarriages

'Arrive: Quoted by Baer and Laquer. Die Trunksucht und ihre Abwehr, p. 89. 
against 0.64 per cent in the latter. Bourneville ${ }^{3}$ found in idiot and epileptic children that in 35 per cent the father was alcoholic and in only 3 per cent was the mother alcoholic. The effect of alcoholic parentage in idiots and epileptics some observers give as high as 85 per cent.

\section{Conclusions.}

We might go on indefinitely quoting statistics but they would, in the main, only substantiate the views based upon what we have already quoted; i. e., that alcohol accounts for an alarming number of the commitments in the insane hospitals to-day both directly, indirectly, and through inherited influences, and that this percentage is slowly but steadily increasing.

The statistics given by Kraepelin are noteworthy from the fact that the Germans boast that alcohol (in the form of beer-drinking) does not effect them as a nation. But these statistics would tend to refute that theory and I have no doubt that the statistics compiled from other communities, would coincide with those of Kraepelin. That a people can become immune to the effects of alcohol through generations of drinking habits, an often quoted theory by those who would uphold drinking in European countries, has been entirely discredited. That they may be able to drink more without its affecting them, may be true, but there is no reason to believe that they are not subject to the same harmful effects of alcohol in both body and mind, as in those countries where habitual drinking has not been the order for centuries.

The problem as presented in this country and that abroad is distinctly different, in that the difficulties in the way of education are much greater abroad than here. This is partially true because of the difference in the traditions and habits regarding drinking that holds sway in the two countries. With us, although alcoholism is increasing, still drinking as such is frowned upon and the youth of the country from moral and religious reasons, are taught to abstain from alcohol, although they may depart from this teaching later. Contrast this state of affairs, with the conditions in Germany, for example, where not only is drinking upheld, but people from childhood on are taught that it is not only right but necessary to the life of the individual.

Bourneville: Recherches cliniques, etc. Paris, 1904 
Among the uneducated classes hardly a man can be found who does not believe that beer is as necessary to him as food and this belief is also shared to some extent by the better educated people. Coupled with these views is the custom of regularly giving children and even babies beer, so that the problem of education of the masses regarding alcohol is an extremely difficult one.

We certainly have no such education of the masses to undertake and hence the problem here though difficult enough, cannot be compared with that in Europe. We cannot but admire such men as Kraepelin and Forel who are leaders in the anti-alcohol agitation abroad, and at the risk of being considered fanatical by a large majority of the people, not only preach total abstinence but practice it as well. With them there is no middle ground for they believe that total abstinence is the only solution of their problem.

From the data presented in this brief communication, I think we are justified in concluding that the problem with us is serious enough and worthy of our thoughtful consideration. 